\title{
Culture medium, gas atmosphere and MAPK inhibition affect regulation of RNA-binding protein targets during mouse preimplantation development
}

\author{
Michele D Calder ${ }^{1,2,3}$, Patricia H Watson ${ }^{1,4,5}$ and Andrew J Watson ${ }^{1,2,3}$ \\ ${ }^{1}$ Departments of Physiology and Pharmacology and ${ }^{2}$ Obstetrics and Gynaecology, The University of Western Ontario, \\ London, Ontario, Canada, ${ }^{3}$ A5-146 Victoria Research Laboratories, Children's Health Research Institute, 800 \\ Commissioners Road East, London, Ontario, Canada N6A 4G5, ${ }^{4}$ Department of Medicine, The University of Western \\ Ontario, London, Ontario, Canada and ${ }^{5}$ Lawson Health Research Institute, London, Ontario, Canada
}

Correspondence should be addressed to M D Calder at A5-148 Victoria Research Laboratories, Children's Health Research Institute, 800 Commissioners Road East, London, Ontario, Canada N6C 2V5; Email: michele.calder@schulich.uwo.ca

\begin{abstract}
During oogenesis, mammalian oocytes accumulate maternal mRNAs that support the embryo until embryonic genome activation. RNA-binding proteins (RBP) may regulate the stability and turnover of maternal and embryonic mRNAs. We hypothesised that varying embryo culture conditions, such as culture medium, oxygen tension and MAPK inhibition, affects regulation of RBPs and their targets during preimplantation development. STAU1, ELAVL1, KHSRP and ZFP36 proteins and mRNAs were detected throughout mouse preimplantation development, whereas Elavl 2 mRNA decreased after the two-cell stage. Potential target mRNAs of RBP regulation, Gclc, Slc2a1 and Slc7a1 were detected during mouse preimplantation development. Gclc mRNA was significantly elevated in embryos cultured in Whitten's medium compared with embryos cultured in KSOMaa, and Gclc mRNA was elevated under high-oxygen conditions. Inhibition of the p38 MAPK pathway reduced Slc7a1 mRNA expression while inhibition of ERK increased Slc2a1 mRNA expression. The half-lives of the potential RBP mRNA targets are not regulated in parallel; Slc2a1 mRNA displayed the longest half-life. Our results indicate that $m R N A s$ and proteins encoding five RBPs are present during preimplantation development and more importantly, demonstrate that expression of RBP target mRNAs are regulated by culture medium, gas atmosphere and MAPK pathways.

Reproduction (2011) 142 689-698
\end{abstract}

\section{Introduction}

The embryonic culture environment exerts a profound influence on the developmental capacity and gene expression patterns of mammalian preimplantation embryos (Ho et al. 1994, Niemann \& Wrenzycki 2000, Watson et al. 2000). There is increasing use of longer culture intervals for the production of human blastocysts in vitro (Jones \& Trounson 1999) but there are concerns that assisted reproductive technologies and embryo culture are associated with increased early embryo loss, foetal growth abnormalities, disruptions in imprinting, alterations in behaviour and enhanced susceptibility to disease in later life (Sinclair et al. 1999, FernandezGonzalez et al. 2004, Watkins et al. 2007, Owen \& Segars 2009).

The primary mechanisms that are proposed to understand culture-induced changes in embryonic gene expression patterns include alterations in transcription and/or epigenetic reprogramming (Doherty et al. 2000, Niemann \& Wrenzycki 2000, Rizos et al. 2003, Watkins et al. 2007). We suggest that at least one additional regulatory mechanism exists that has not been largely considered to date. While it is known that mRNA deadenylation/polyadenylation occurs during oocyte maturation (Brevini-Gandolfi et al. 1999), only a very few studies have begun to examine the influences of varying culture environments on embryo mRNA adenylation and mRNA stability (Ho et al. 1994).

RNA-binding proteins (RBP) influence RNA editing, localisation, stability and translation (Saunders \& Barber 2003). Regulated mRNA stability occurs in mammalian cells in response to nutrient levels, hormones and environmental stresses such as hypoxia and heat stress (reviewed in Guhaniyogi \& Brewer (2001)). There has been little research on the roles of RBPs in mammalian germ cells, oocytes or early embryos. Staufen was first identified in the Drosophila oocyte as an RBP involved in establishing anterior-posterior axis specification (St Johnston et al. 1991), and has a role in mRNA decay (Kim et al. 2005). ELAVL1 protein (HuR) is a widely expressed mammalian RBP (Fan \& Steitz 1998) whose localisation is regulated by various stresses 
(Yaman et al. 2002, Song et al. 2005) involving the p38 MAPK pathway (Tran et al. 2003, Song et al. 2005). ELAVL1 protein binds to AU-rich elements (ARE) and increases the stability (Fan \& Steitz 1998) and translation of ARE-containing mRNAs (Peng et al. 1998). Similarly, ELAVL2 (HuB) also binds ARE, slows mRNA degradation and may increase protein translation (Jain et al. 1997). ZFP36 (tristetraprolin, TTP) is an RBP whose activity is regulated by p38 MAPK (Brook et al. 2006). ZFP36 promotes deadenylation of ARE-containing mRNAs and increases their degradation rate (Lai et al. 2000). $\mathrm{KH}$-type splicing regulatory protein (KHSRP) is another RBP regulated by MAPK that degrades ARE-containing mRNAs (Briata et al. 2005). These studies suggest that several RBPs may mediate environmental influences on transcript stability and translation via the p38 MAPK pathway.

We examined the effects of good and poor culture environments on mRNA abundance and stability. The effects of the culture environment may be communicated to the embryo by the activation of pathways such as the p38 MAPK pathway (Natale et al. 2004). Our laboratory has discovered that the p38 MAPK pathway is activated in embryos in response to osmotic stress (Fong et al. 2007). In the current studies, we investigated whether culturing embryos in a good medium (KSOMaa, $0.2 \mathrm{mM}$ glucose and amino acids) or poor medium (Whitten's medium containing $5.55 \mathrm{mM}$ glucose and no amino acids) affects RBP expression and the expression of ARE-containing target genes. Development, the number of ICM cells and total cell number in blastocysts is reduced in embryos cultured in Whitten's medium compared with KSOMaa (Rinaudo et al. 2006). Our second model of environmental stress examined the effect of incubator oxygen tension on mRNA abundance and stability. Mouse studies have shown for some years (Harlow \& Quinn 1979), but more recently human studies have also shown improved developmental and pregnancy rates (Kovacic \& Vlaisavljević 2008, Meintjes et al. 2009, Waldenström et al. 2009) when cultured under a lower oxygen tension (5\%) than conventionally used $(20 \%)$. Furthermore, high oxygen tension greatly increases the number of genes aberrantly expressed in the mouse embryo (Rinaudo et al. 2006).

For these reasons, we have focused our studies on characterising the expression of STAU1, ELAVL1, ELAVL2, KHSRP and ZFP36 RBPs at the mRNA and protein level, during preimplantation development in the mouse. Three RBP target mRNAs were selected, as all are identified as targets of ELAVL1 in other tissues (Yaman et al. 2002, Song et al. 2005, Gantt et al. 2006). $\gamma$-Glutamylcysteine ligase catalytic unit (GCLC) is a key enzyme involved in synthesis of glutathione, which reacts to cellular stresses and deactivates destructive reactive oxygen species (Meister 1994). SLC2A1 (GLUT1) is a glucose transporter that is expressed in the preimplantation embryo (Moley et al. 1998). SLC7A1
(CAT1) is an arginine/lysine transporter involved in both trophoblast outgrowth and signalling for implantation (Martin et al. 2003).

Our results indicate that mRNAs and proteins encoding these five RBPs are present during preimplantation development. Importantly, their target mRNAs are affected by culture environment. These results establish a foundation for investigating the roles of RBPs during early development and more importantly, their collective roles in regulating transcript stability and translation during early embryogenesis.

\section{Results \\ Protein localisation}

ELAVL1 protein was observed in the cytoplasm of oocytes and all embryo stages and was nuclear in some embryos at all stages examined (Fig. 1). ELAVL2 protein immunofluorescence was detected in the cytoplasm of oocytes and embryos at all stages examined (Fig. 1), ELAVL2 was frequently observed in the nuclei but not to the same extent as ELAVL1. KHSRP protein was detected across preimplantation development in both nuclei and cytoplasm (Fig. 1). ZFP36 protein was detected in the cytoplasm and nuclei at all stages throughout preimplantation development (Fig. 1), and included the unique feature of encircling the nucleus in a ring-like fashion. STAU1 protein immunofluorescence was localised to the cytoplasm and in some nuclei (Fig. 1). It was not unusual to also observe punctuate fluorescent foci in the cytoplasm that were suggestive of a non-uniform localisation. GCLC protein was predominantly localised to the cytoplasm at all stages examined (Fig. 2), but interestingly, was also associated with the spindle during mitosis (arrow). GCLC protein fluorescence increased at the blastocyst stage. SLC2A1 protein was quite low in early preimplantation stages but increased markedly at the blastocyst stage (Fig. 2), where it was often localised to cell membranes. SLC7A1 protein was barely detectable in early stages, but was clearly present in the trophectoderm basal membrane at the blastocyst stage (Fig. 2).

\section{Developmental expression}

Elavl1 mRNA levels were significantly higher at the blastocyst stage than at earlier developmental stages (Fig. 3A) as were Gclc (Fig. 3F), Slc2a1 (Fig. 3G) and Slc7a1 mRNAs (Fig. 3H). Elavl2 mRNA levels were highest at the two-cell stage and were significantly lower at the eight-cell and morulae stages (Fig. 3B). For Khsrp (Fig. 3C), Zfp36 (Fig. 3D) and Stau1 mRNAs (Fig. 3E) there was no significant variance in mRNA levels across embryonic stages. 
ELAVL1
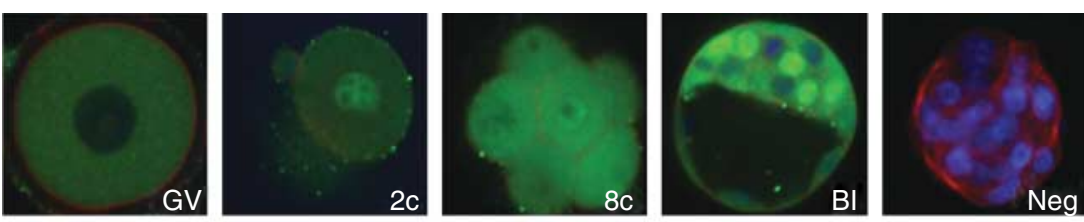

ELAVL2
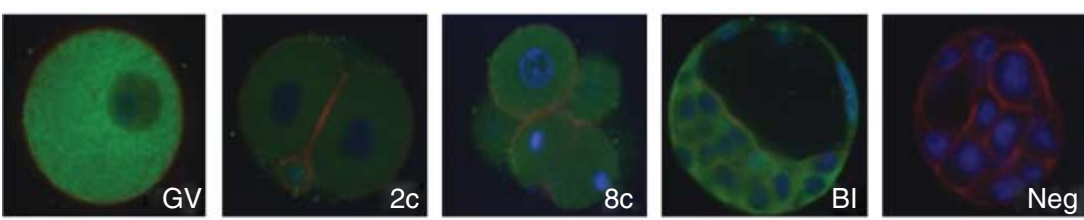

KHSRP
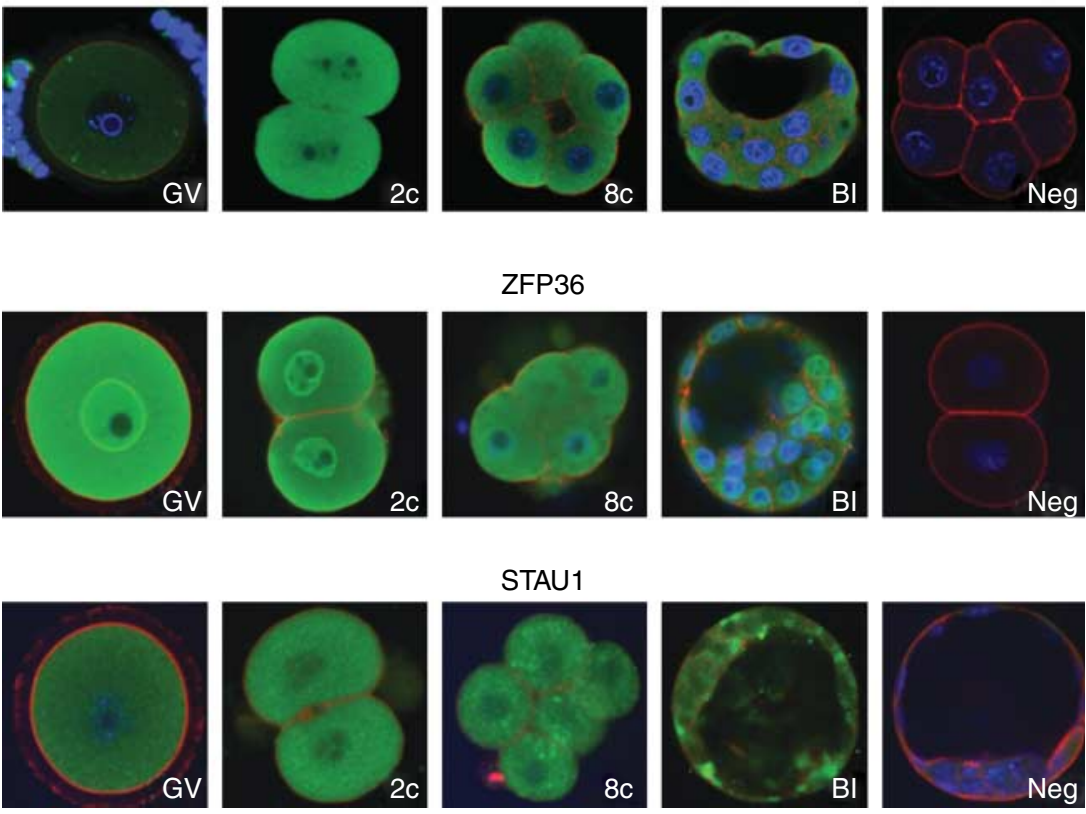

Figure 1 Localisation of STAU1, ELAVL1, ELAVL2, KHSRP and ZFP36 proteins during mouse preimplantation development. Green is RBP fluorescence. Red is rhodamine-phalloidin staining of F-actin. Blue is DAPI-stained DNA. GV, germinal vesicle stage; $2 \mathrm{C}$, two-cell stage; $8 \mathrm{c}$, eight-cell stage; $\mathrm{Bl}$, blastocyst stage; Neg, negative control.

\section{Influence of culture on RBP and RBP target expression}

\section{Culture medium}

To test our hypothesis that culture environment would influence RBP expression and thus levels of their target mRNAs, we contrasted mRNA levels between embryos cultured in KSOMaa (good culture medium) and Whitten's medium (substandard medium). As in the developmental series, Elavl1 mRNA levels were affected by stage $(P<0.001$, Fig. 4A), but there was no effect of medium or interaction. For Khsrp mRNA, there were no significant effects of media, stage or interaction (Fig. 4B). There was an effect of stage for Zfp36 mRNA (Fig. 4C, $P<0.004)$, expression was higher at the four-cell stage than the eight-cell and blastocyst stages, but no effect of medium or interaction. For potential RBP target mRNAs, there was a significant effect of medium on Gclc (Fig. 4D, $P<0.049$ ), mRNA levels were higher in embryos cultured in Whitten's medium than in KSOMaa. For Slc2a1, there was a significant effect of stage (Fig. 4E, $P<0.001$ ), with mRNA levels higher in blastocysts and morulae than in four- and eight-cell stage embryos. For Slc7a1 mRNA, due to low levels at other stages, we compared only blastocysts and there was no effect of medium (Fig. 4F, $P<0.12$ ).

\section{Culture atmosphere}

Gclc mRNA levels were significantly higher in the high$\mathrm{O}_{2}$ atmosphere than the low-oxygen atmosphere (Fig. 5A, $P<0.054$ ). Neither Slc2a1 (Fig. 5C, $P<0.324$ ) nor Slc7a1 mRNAs (Fig. 5E, $P<0.166$ ) were affected by gas atmosphere. There were no significant effects of gas atmosphere on any of the RBP mRNAs (data not shown), Elavl1 $(P<0.742)$, Khsrp $(P<0.145)$ and Zfp36 $(P<0.313)$. 

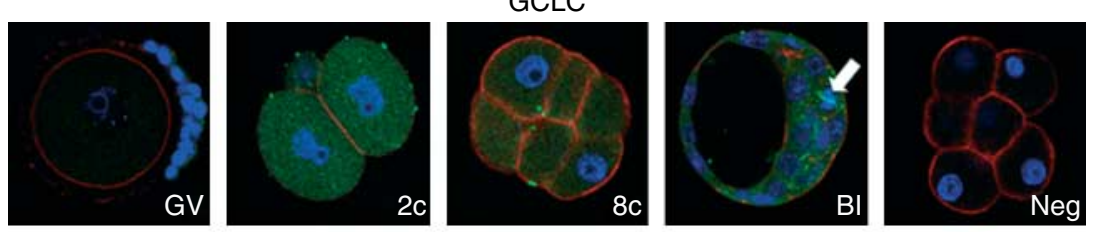

SLC2A1
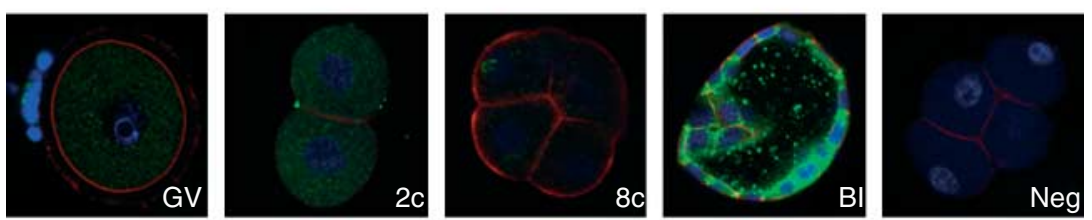

SLC7A1
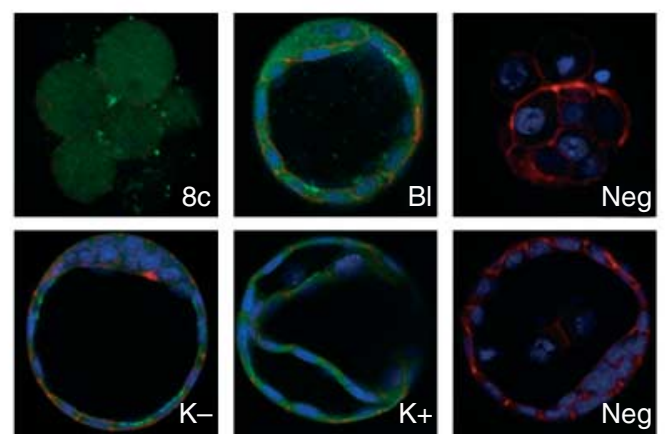

Figure 2 Localisation of GCLC, SLC2A1 and SLC7A1 proteins during mouse preimplantation development. Green is target protein fluorescence. Red is rhodamine-phalloidin stain for F-actin. Blue is DAPI-stained DNA. GV, germinal vesicle stage; $2 \mathrm{c}$, two-cell stage; $8 \mathrm{c}$, eight-cell stage; $\mathrm{Bl}$, blastocyst stage; $\mathrm{K}-$, amino acids withdrawn for $18 \mathrm{~h}$; $\mathrm{K}+$, amino acids present; $\mathrm{Neg}$, negative control. Staining of the spindle in GCLC is indicated by the arrow.

\section{mRNA half-life}

Target gene mRNAs were investigated to determine whether the mRNAs decayed with similar kinetics under high- or low-oxygen conditions. For the Gclc regression line, the significance for the overall analysis was $P<0.001$, and the adjusted $R^{2}$ value was 0.558 . For treatment (high versus low oxygen) the $P$ value was 0.163 , for hour was $P<0.001$, while the replicate was $P<0.001$ (Fig. 5B). Gclc mRNA half-life was $\sim 7$ h. For the Slc2a1 mRNA regression, there was an overall $P<0.001$, and the adjusted $R^{2}$ value was 0.410 (Fig. 5D). The $P$ value for treatment was 0.734 , for hour $P<0.001$ and for replicate, $P<0.001$. The half-life of Slc2a1 mRNA was $\sim 10.5 \mathrm{~h}$. For Slc7a1 mRNA (Fig. 5F), there was an overall $P<0.001$ for the regression, and the adjusted $R^{2}$ value was 0.576 . The $P$ value for treatment was 0.079 , for hour was $P<0.001$, and for replicate was $P<0.001$. The half-life for Slc7a1 mRNA was $\sim 8.5 \mathrm{~h}$.

\section{Regulation by MAPKs}

For the target genes, p38 MAPK inhibition with SB220025 significantly reduced Slc7a1 mRNA (Fig. 6C, $P<0.001$ ). We also observed a trend towards decreased Slc2a1 mRNA levels (Fig. 6B, $P<0.09$ ). P38 MAPK inhibition did not affect Gclc mRNA. When ERK1/2 MAPK activation was inhibited by UO126, Slc2a1 mRNA levels significantly increased (Fig. 6E,
$P<0.04)$. We observed no effect of the SP600225 drug (JNK/SAPK inhibition) on mRNA levels. Inhibition of the various MAPKs also did not significantly affect RBP mRNA levels (data not shown).

\section{Discussion}

We have discovered that mRNAs and proteins encoding five RBPs (STAU1, ELAVL1, ELAVL2, KHSRP and ZFP36) are present during mouse preimplantation development. Elavl1 mRNA increased to the blastocyst stage, which agrees with qRT-PCR and microarray studies (Evsikov et al. 2004, Zeng et al. 2004). We report both cytoplasmic and nuclear protein expression in mouse embryos here that agrees with previous mouse and bovine studies (Evsikov et al. 2004, Calder et al. 2008). Although ELAVL1 protein localisation has been reported as mostly nuclear in several cell types (Fan \& Steitz 1998, Peng et al. 1998) when activated by stress ELAVL1 moves to the cytoplasm (Peng et al. 1998) where it protects ARE-containing mRNAs from degradation (Fan \& Steitz 1998). Elavl2 mRNA decreased after the two-cell stage by qRT-PCR analysis, evidence of maternal expression, which agrees with qRT-PCR and microarray studies of preimplantation embryos (Evsikov et al. 2004, Zeng et al. 2004). ELAVL2 protein was expressed at all stages in the nuclear and cytoplasmic compartments, similar to what was been observed in bovine embryos (Calder et al. 2008). However, ELAVL2 protein apparently decreased 

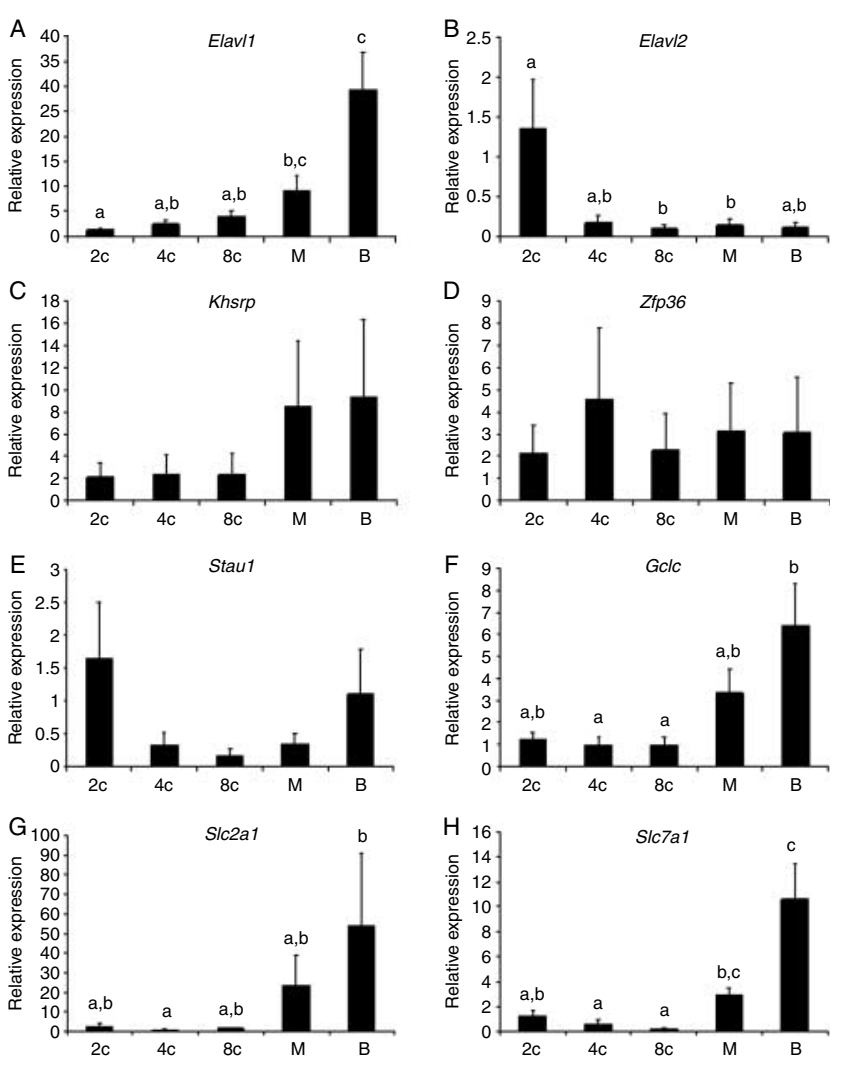

Figure 3 Expression of RBP mRNAs and potential target gene mRNAs by real-time qRT-PCR during mouse preimplantation development. A, Elavl1; B, Elavl2; C, Khsrp; D, Zfp36; E, Stau1; F, Gclc; G, Slc2a1; H, Slc7a1. 2c, Two-cell stage; 4c, four-cell stage; 8c, eight-cell stage; M, morulae stage; $B$, blastocyst stage. ${ }^{a, b, c}$ Bars with no letters in common are significantly different. There were four independent replicates for each gene.

after the zygote stage in a previous study (Evsikov et al. 2004). As Elav/2 mRNA decreases after the two-cell stage, it is likely that some maternal protein persists to the blastocyst stage. It has been suggested that these two ELAV proteins may control translation of maternal mRNAs in the mouse embryo (Evsikov et al. 2004).

Expression of KHSRP protein was detected here in mouse and bovine embryos (Calder et al. 2008) in both the cytoplasmic and nuclear compartments. ZFP36 protein was localised to the cytoplasm, nucleus and nuclear envelope of mouse embryos and had previously been reported to shuttle between the nucleus and cytoplasm in other tissues (Phillips et al. 2002). STAU1 protein is both nuclear and cytoplasmic here in mouse embryos and in bovine embryos (Calder et al. 2008). The presence of these three RBPs in the embryo suggests roles in mRNA decay as reported in other tissues (Lai et al. 2000, Briata et al. 2005, Kim et al. 2005).

RNAs of three known targets of ELAVL1 regulation, Slc7a1, Gclc and Slc2a1 (Yaman et al. 2002, Song et al. 2005, Gantt et al. 2006), which contain 3' UTR-like ARE sequences, all increased in expression at the blastocyst stage. Our data are consistent with detection of Gclc
mRNA and protein only at the mouse blastocyst stage (Stover et al. 2000). The increase in S/c2a1 mRNA (Zeng et al. 2004) and protein, especially at the cell membrane, at the blastocyst stage is consistent with earlier studies (Pantaleon et al. 2001) and with the timing of the change in embryo metabolism from lactate/pyruvate to glucose utilisation (Gardner \& Leese 1986). Slc7a1 is involved in both trophoblast outgrowth and in synthesis of nitric oxide for implantation (van Winkle 2001, Martin et al. 2003). Although the mRNA was reported to be detectable from two-cell to blastocyst stage previously (van Winkle 2001), here mRNA expression was observed to increase at the blastocyst and the protein began to be expressed at the basal membrane surrounding the blastocyst cavity.

Importantly, we discovered that culture conditions and MAPKs have a significant impact on the mRNA levels of these RBP targets. Gclc mRNA was significantly elevated in embryos cultured under high oxygen tension. Increased reactive oxygen species have been previously detected in embryos cultured under high-oxygen conditions (Goto et al. 1993). Expression of Gclc mRNA was also higher in Whitten's medium compared with embryos cultured in KSOMaa. Differences in Gclc mRNA expression may be linked to changes in metabolism leading to the generation of reactive oxygen species. Slc2a1 mRNA was not significantly lower in
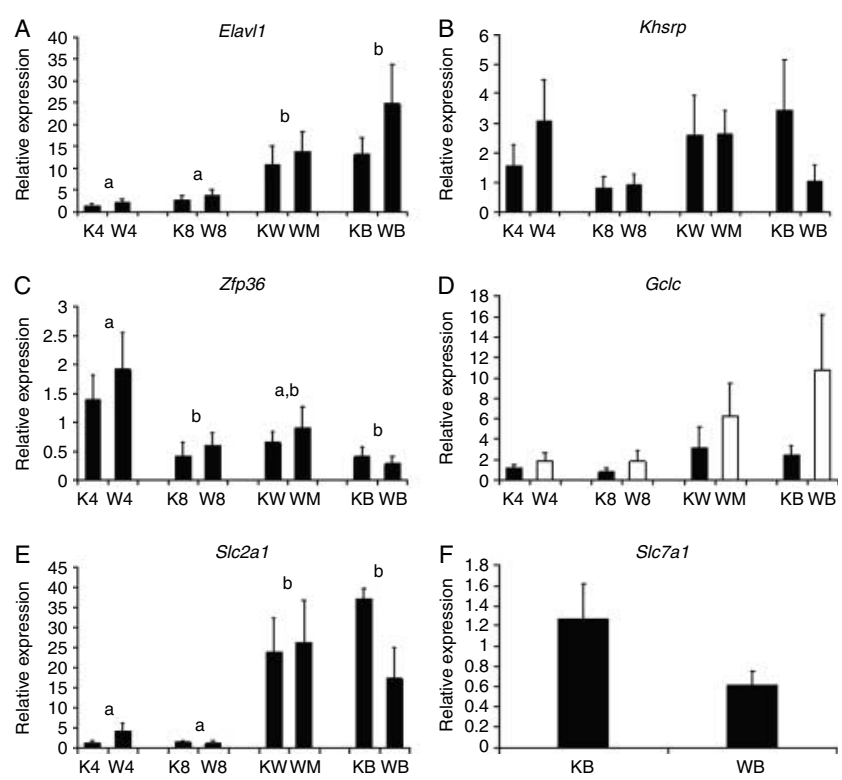

Figure 4 Influence of a poor or more optimised culture medium on RBP and target mRNA expression by real-time qRT-PCR during mouse preimplantation development. A, Elavl1; B, Khsrp; C, Zfp36; D, Gclc; E, Slc2a1; F, Slc7a1. K, KSOMaa; W, Whitten's medium. 4c, Four-cell stage; 8c, eight-cell stage; $M$, morulae stage; B, blastocyst stage. Different coloured bars indicate a significant effect of medium. ${ }^{\mathrm{a}, \mathrm{b}} \mathrm{A}$ significant difference between stages is indicated by bars without a letter in common $(P<0.05)$. There were four replicates for except $S / c 2 a 1$, where there were three replicates. For $S / c 7 a 1$, only blastocysts are compared, there were five replicates. 

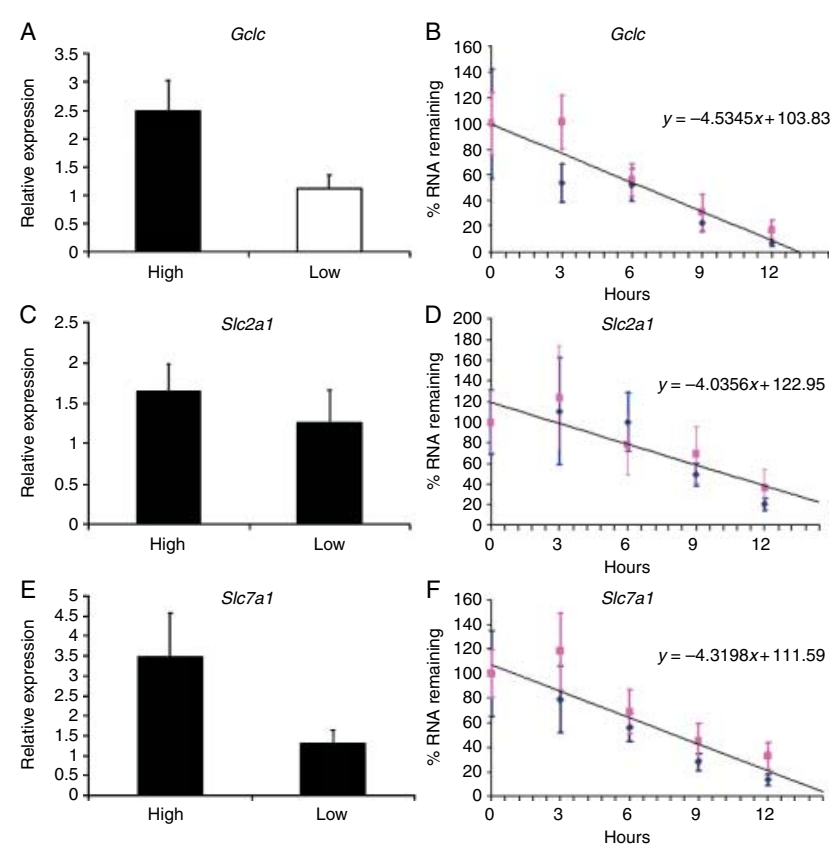

Figure 5 Influence of culture under a high- $(\mathrm{H}, 20 \%)$ or low-oxygen $(\mathrm{L}, 5 \%)$ atmosphere on target mRNA expression and decay using realtime qRT-PCR. mRNA abundance A, Gclc; C, Slc2a1; E, Slc7a1. There were six independent replicates, except for $S / c 7 a 1$ mRNA where $N=7$. Different coloured bars indicate a significant effect of oxygen, $P<0.054$. mRNA decay B, Gclc; D, Slc2a1; F, Slc7a1. There were five replicates. The pink square symbols are low oxygen and the blue diamond symbols are high oxygen mean and standard error. The average decay rate is indicated by the black line and the calculation for slope is indicated.

embryos cultured in Whitten's medium containing higher glucose than KSOMaa. Earlier studies demonstrated lower expression of S/c2a $1 \mathrm{mRNA}$ and protein in blastocysts developing in diabetic compared with normoglycaemic mice (Moley et al. 1998). There were no effects of oxygen tension on Slc2a1 mRNA, similar to previous results in mouse embryos (Kind et al. 2004). Surprisingly, Slc7a1 mRNA was not expressed at different levels between embryos cultured in KSOM that contains amino acids, compared with Whitten's medium that is not supplemented with amino acids. Amino acids are necessary at $\sim 120 \mathrm{~h}$ post human chorionic gonadotrophin (hCG) for blastocyst trophoblast outgrowth to occur (Martin et al. 2003).

Target gene mRNAs were examined to determine whether the decay kinetics were similar under high- or low-oxygen conditions. Pipetting embryos can increase MAPK activation (Xie et al. 2007), and $\boldsymbol{\alpha}$-amanitin may not completely block mRNA transcription until $2 \mathrm{~h}$ of treatment (Kidder et al. 1985), which may explain why some transcript levels are higher at the $3 \mathrm{~h}$ timepoint than at $0 \mathrm{~h}$. Nonetheless, Slc7a1 mRNA tended to decay faster in the higher oxygen environment. Our calculations for mRNA half-lives for Gclc, Slc2a1 and Slc7a1 were all longer than those calculated from a microarray study of mouse ES cells (Sharova et al. 2009). However, the half-life for Gclc mRNA in our study is similar to that in colorectal cells of 6.3-6.8 h (Song et al. 2005). The half-life for S/c2a1 mRNA in embryos was twice as long as for ES cells.

Our laboratory has shown that treatment of early embryos with p38 MAPK inhibitors resulted in a blockade of early development (Natale et al. 2004), in addition, we demonstrated that p38 MAPK regulates the embryo's response to osmotic stress (Fong et al. 2007). Furthermore, ELAVL1, KHSRP and ZFP36 are all regulated by the p38 MAPK pathway (Brook et al. 2006, Tran et al. 2003, Briata et al. 2005). Therefore, we tested the effects of inhibitors of three different MAPK pathways on RBP and target mRNA expression. MAPK inhibitors had no effects at the mRNA level of these RBPs, however, RBPs are usually regulated the protein level by phosphorylation or changing the nuclear/ cytoplasmic localisation (Brook et al. 2006, Tran et al. 2003, Briata et al. 2005). Slc7a1 mRNA was significantly reduced by $\mathrm{p} 38$ MAPK inhibitor but not by the other MAPK inhibitors. This observation is in agreement with earlier research demonstrating that induction of $S / c 7 a 1$ mRNA was reduced by inhibiting the p38 pathway (Baydoun et al. 1999). Slc2a1 mRNA expression increased when the ERK MAPK pathway was inhibited.

In conclusion, mRNAs and proteins encoding STAU1, ELAVL1, ELAVL2, KHSRP and ZFP36 are expressed during preimplantation development. These RBPs regulate mRNAs via effects on stability, translation or repression. Several studies that contrasted mRNA levels in embryos cultured under different conditions have suggested that transcriptional activity largely governs changes in mRNA abundance (Niemann \& Wrenzycki 2000, Rizos et al. 2003). However, mRNA levels are a balance between rate of transcription and the rate of degradation (Guhaniyogi \& Brewer 2001). Our results have initiated studies directed towards an eventual understanding of the role RBPs play in controlling mRNA turnover and stability during mammalian oocyte maturation and early embryogenesis.

\section{Materials and Methods}

\section{Mouse embryos and developmental series}

Four-week-old female MF-1 mice and adult male CD-1 mice were obtained from Charles River Laboratories International, Inc. (Wilmington, MA, USA; CD-1) or Harlan Laboratories, Inc. (Indianapolis, IN, USA; MF-1). Females were injected with $7.5 \mathrm{IU}$ pregnant mare serum gonadotrophin (PMSG; Folligon, Intervet, Whitby, ON, Canada) to stimulate follicular development, followed by $7.5 \mathrm{IU}$ hCG (Chorulon, Intervet) 46-48 h after PMSG and placed with a male for mating, day of copulation plug is considered D1. Germinal vesicle (GV) stage oocytes were collected $48 \mathrm{~h}$ after PMSG. Ovaries were removed and placed into M2 medium (Sigma). Large follicles were punctured with $30 \mathrm{~g}$ needles and large oocytes with 

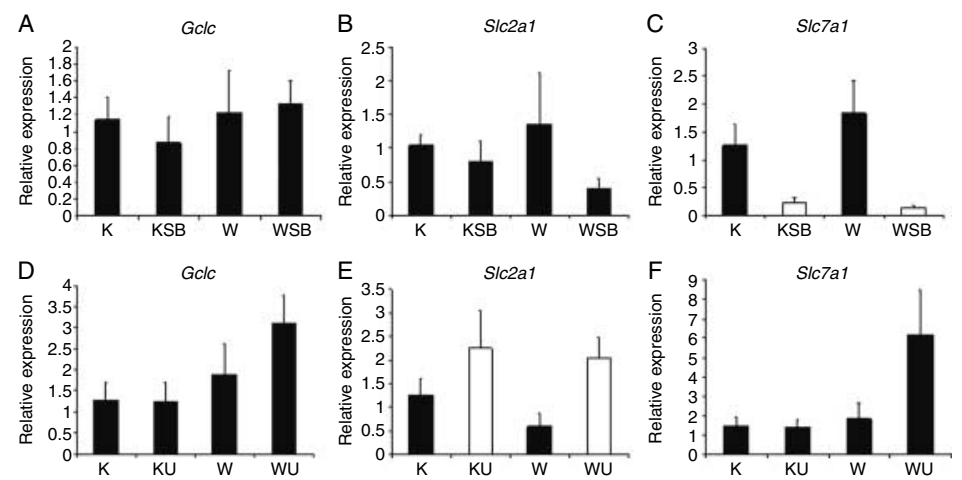

Figure 6 Influence of culture in KSOMaa (K) or Whitten's medium (W) and MAPK inhibitors on target mRNA expression measured by qRT-PCR. (A-C) DMSO control or p38 inhibitor SB220025 (SB) A, Gclc; B, Slc2a1; C, Slc7a1. (D-F) DMSO
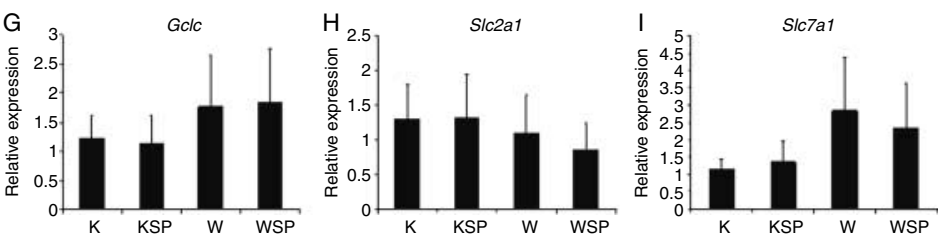
control or inhibitor of ERK1/2 activation, UO126 (U) D, Gclc; E, Slc2a1; F, Slc7a1. (G-I) DMSO control or JNK/SAPK inhibitor SP600225 (SP) G, Gclc; H, Slc2a1; I, Slc7a1. K, KSOMaa, W, Whitten's medium. Different coloured bars indicate a significant effect of the MAPK inhibitor. There were five replicates for all except S/c2a1 with the p38 inhibitor, where there were four replicates.

compact GV were collected, vortexed to remove cumulus and washed extensively. Later developmental stages were collected by flushing two-cell embryos from oviducts with M2 on D2 and placing embryos into culture in KSOMaa (Millipore, Phillipsburg, NJ, USA) at $37{ }^{\circ} \mathrm{C}$ in $5 \% \mathrm{O}_{2}, 5 \% \mathrm{CO}_{2}$ and $90 \% \mathrm{~N}_{2}$ atmosphere. Two-cell embryos were collected at $46-48 \mathrm{~h}$ post hCG, four-cell embryos at $66 \mathrm{~h}$, eight-cell embryos at $72 \mathrm{~h}$, morulae at about $90 \mathrm{~h}$ and blastocysts at 96-100 h. Animal care and handling was according to the guidelines of the University of Western Ontario Animal Care Committee approved by the Canadian Council on Animal Care.

\section{Whole-mount immunofluorescent confocal microcopy}

For immunofluorescent microscopy, pools of embryos at the different stages were fixed in $2 \%$ paraformaldehyde in PBS for $20 \mathrm{~min}$ at room temperature and stored in PHEM $(60 \mathrm{mM}$ PIPES, $25 \mathrm{mM}$ HEPES, $10 \mathrm{mM}$ EGTA and $1 \mathrm{mM} \mathrm{MgCl}-6 \mathrm{H}_{2} \mathrm{O}$ ) buffer at $4{ }^{\circ} \mathrm{C}$. For immunostaining, fixed embryos were permeabilised and blocked in $1 \times$ PBS $+5 \%$ goat or donkey serum (Cedarlane, Burlington, ON, Canada) $0.01 \%$ Triton $\mathrm{X}-100$ for $1 \mathrm{~h}$ at room temperature (Madan et al. 2007). Rabbit polyclonal anti-human STAU1 (1:100), ELAVL1 (1:50) and ELAVL2 (1:100) antibodies were obtained from Chemicon (Temecula, CA, USA). Anti-KHSRP (1:100) was obtained from Cedarlane and anti-ZFP36 (1:100), anti-SLC2A1 (1:100) and anti-GCLC (1:50) antibodies were obtained from Abcam (Cambridge, MA, USA). Two anti-SLC7A1 (CAT1) antibodies were assayed, the first was a rabbit anti-mouse polyclonal used at 1:50 (Santa Cruz Biotechnology, Inc., Santa Cruz, CA, USA; sc-66825). The second was rabbit anti-human polyclonal antibody used at 1:50, obtained from Proteintech (Chicago, IL, USA, 14195-1-AP). Embryos were counterstained with rhodamine-phalloidin to stain actin and DAPI to stain DNA (Madan et al. 2007). Negative control embryos were not exposed to primary antibody. Embryos were examined by confocal laser scanning microscopy (Olympus FV1000, Olympus Canada, Inc., Markham, ON, Canada).

\section{Quantitative PCR-RNA extraction and RT}

Total RNA was extracted from pools of 50 frozen embryos (two-, four- and eight-cells, morulae and blastocyst), using a Picopure kit (Arcturus, Mountain View, CA, USA). There were four distinct replicates to demonstrate mRNA expression across preimplantation development. Samples were spiked with exogenous control Luciferase mRNA (Promega Corporation) at $0.025 \mathrm{pg} / \mathrm{embryo}$ before extraction (Fong et al. 2007). Removal of genomic DNA was performed with a DNAse digestion step (Qiagen). Following extraction, the volume was $12 \mu \mathrm{l}$. RNA samples were RT with Sensiscript (Qiagen) in a mix containing $2 \mu \mathrm{l} 10 \times$ buffer, $2 \mu \mathrm{l} 5 \mathrm{mM}$

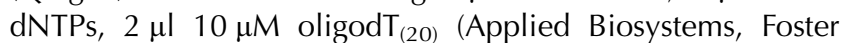
City, CA, USA), $1 \mu \mathrm{l} 10 \mathrm{U} / \mu \mathrm{l}$ RNAse inhibitor (Invitrogen) and $1 \mu \mathrm{l}$ Sensiscript in a volume of $20 \mu \mathrm{l}$.

For real-time qRT-PCR, we used the external (Luciferase) control for quantification. PCR was performed in an ABI PRISM 7900HT sequence detection system (Applied Biosystems) using TaqMan Gene Expression Assays (Applied Biosystems). A custom TaqMan primer and probe set for Luciferase were designed using the Applied Biosystems Assays-by-Design File Builder programme (Fong et al. 2007). In addition, commercially available TaqMan Gene Expression Assays for Elavl1 (Assay ID: Mm00516011_m1), Elavl2 (Assay ID: Mm00516015_m1), Khsrp (Assay ID: Mm01232838_g1), Zfp36 (Assay ID: Mm00457144_m1), Stau1 (Assay ID: Mm00488462_m1) and Gclc (Assay ID: Mm00802655_m1) were also used. For Slc2a1 (Assay ID: Mm00441473_m1, exons 1-2 boundary) was used for the developmental series and culture medium experiments but for later experiments Assay Mm01192272_g1 (exons 9-10 boundary) was used because it was closer to the $3^{\prime}$ end of the mRNA, amplified better with oligodT and had greater sensitivity. Because the 3' UTR of Slc7a1 is very long, predesigned primers did not amplify well after RT. Therefore, primers and a fluorescent probe were designed using the Assays-by-Design File Builder programme within the mouse Slc7a1 3' UTR region, ordered 
from Applied Biosystems and validated. Standard thermal cycling conditions were applied as in previous experiments (Fong et al. 2007) for 60 cycles. However, for Slc7a1, the PCR mixture contained $1.875 \mu \mathrm{l}$ of each primer, $0.0867 \mu \mathrm{l}$ of the fluorescent probe and $0.33 \mu \mathrm{l}$ water per $25 \mu \mathrm{l}$ reaction. Each sample was measured in triplicate.

\section{Influence of culture on RBP and RBP target expression}

\section{Culture medium}

Mice were superovulated as described earlier. Two-cell embryos were flushed from oviducts with M2 on D2 and embryos were washed with KSOMaa or Whitten's medium (Whitten \& Biggers 1968) and placed into culture at $37^{\circ} \mathrm{C}$ in $5 \% \mathrm{CO}_{2}, 5 \% \mathrm{O}_{2}$ and $90 \% \mathrm{~N}_{2}$ atmosphere. Paired Whitten's and KSOMaa samples were collected at each timepoint, but since development was slower in Whitten's medium, more embryos were cultured in Whitten's and blastocysts were collected later, at $114 \mathrm{~h}$, to allow for blastocyst formation to occur. RNA was extracted as above for quantitative qRT-PCR. Due to our interest in genes regulated by p38 MAPK, we assayed for Elavl1, Khsrp, Zfp36, Slc2a1, Gclc and Slc7a1 mRNAs in addition to the control gene, luciferase. There were four replicates, except for S/c2a1 of which there were three.

\section{Culture atmosphere}

Embryos were cultured in KSOMaa medium in either a high(5\% $\mathrm{CO}_{2}$, balance room air $\left.\left(\sim 20 \% \mathrm{O}_{2}\right)\right)$ or low-oxygen $(5 \%$ $\mathrm{O}_{2}, 5 \% \mathrm{CO}_{2}$ and $90 \% \mathrm{~N}_{2}$ ) atmosphere from the two-cell stage to the blastocyst stage ( $96 \mathrm{~h}$ post hCG) and frozen for RNA extraction and real-time qRT-PCR as described earlier. There were six replicates for all genes except Slc7a1 mRNA, for which there were seven.

\section{mRNA half-life}

Target gene mRNAs were examined to determine whether they decayed with similar kinetics under high- or low-oxygen conditions. Embryos were cultured in KSOMaa from the twocell stage until $96 \mathrm{~h}$ under 5 or $20 \%$ oxygen, there were five replicates. Twenty blastocysts were then collected, washed three times and cultured in KSOMaa containing $50 \mu \mathrm{g} / \mathrm{ml}$ $\alpha$-amanitin to inhibit transcription and placed back into either high- or low-oxygen conditions. Embryos were collected at 0 , 3, 6, 9 and $12 \mathrm{~h}$. The amount of mRNA (\%) remaining at each timepoint was compared with $0 \mathrm{~h}$.

\section{MAPK regulation}

Embryos were cultured in KSOMaa or Whitten's from the twocell to $96 \mathrm{~h}$ blastocyst stage under low-oxygen conditions as above. Embryos were then washed three times and placed into the same medium with either DMSO (vehicle control) or active MAPK inhibitor for $18 \mathrm{~h}$ and collected for qRT-PCR, as described earlier. The inhibitors were obtained from EMD Chemicals (Newark, NJ USA) and were diluted stored as $20 \mathrm{mM}$ stock concentrations in DMSO. SB220025 was used at final concentration of $20 \mu \mathrm{M}$ and used to inhibit p38 MAPK. U0126 was used at $20 \mu \mathrm{M}$ as an inhibitor of ERK1/ERK2, and
SP600225 was used at $20 \mu \mathrm{M}$ as an inhibitor of JNK/SAPK. There were five replicates of each, except $S / c 2 a 1$ with the p38 inhibitor, where $N=4$.

\section{Statistical analysis}

For all samples, quantification was normalised to the exogenous control luciferase RNA levels. Expression levels were calculated according to the method of Pfaffl (2001), where expression level is calculated as the ratio between

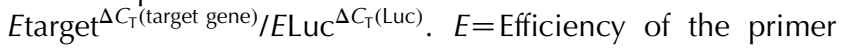
set, which was calculated by the slope of tenfold dilutions of a standard sample according to the formula of $E=10^{(-1 / \mathrm{slope})}$. The $\Delta C_{\mathrm{T}}$ value $=C_{\mathrm{T}}($ avg of control $)-C_{\mathrm{T}}($ each sample $)$. Statistical analysis was performed by SigmaStat 3.5 (Jandel Scientific Software, San Rafael, CA, USA) software package. Real-Time qRT-PCR results are presented as the mean \pm s.E.M.

Real-time qRT-PCR data were log transformed before ANOVA was performed, followed by a Tukey's test for multiple comparisons. In addition, ANOVA was performed on the untransformed values, followed by a Holm-Sidak multiple comparison test. For the developmental experiment, comparisons were made among stages. In the culture medium experiment, the data were analysed by two-way ANOVA after transformation, with the effects of medium, stage and interaction examined, followed by Holm-Sidak multiple comparison tests. For S/C7a1, due to low expression at other stages, only blastocysts were compared by a $t$-test after log transformation. There were five replicates. For the culture gas experiment, $t$-tests were performed. Analysis of mRNA decay was performed with multilinear regression using treatment, hour and replicate as factors after setting the time 0 values to $(100 \%)$, data were left untransformed. In the MAPK experiments, the control was KSOMaa treated with DMSO (vehicle). The data were analysed by two-way ANOVA, with the effects of medium, MAPK inhibitor and interaction examined, followed by Holm-Sidak multiple comparison tests. For all data analyses, $P \leq 0.05$ was considered statistically significant.

\section{Declaration of interest}

The authors declare that there is no conflict of interest that could be perceived as prejudicing the impartiality of the research reported.

\section{Funding}

Research supported by a Natural Sciences and Engineering Research Council of Canada (NSERC) Discovery Grant \#138317-06 to A J Watson.

\section{Acknowledgements}

We thank members of the Watson Laboratory, Christine Bell, Holly Giannatselis, Tamara Abraham, Pavneesh Madan, Jenny Hickson and Barry Fong for help with embryo collections. We thank Doug Fraser for use of the statistical programme, and Bonnie Deroo for help with statistical analyses. 


\section{References}

Baydoun AR, Wileman SM, Wheeler-Jones CP, Marber MS, Mann GE, Pearson JD \& Closs El 1999 Transmembrane signalling mechanisms regulating expression of cationic amino acid transporters and inducible nitric oxide synthase in rat vascular smooth muscle cells. Biochemical Journal 344 265-272. (doi:10.1042/0264-6021:3440265)

Brevini-Gandolfi TA, Favetta LA, Mauri L, Luciano AM, Cillo F \& Gandolfi F 1999 Changes in poly(A) tail length of maternal transcripts during in vitro maturation of bovine oocytes and their relation with developmental competence. Molecular Reproduction and Development 52 427-433. (doi:10.1002/(SICI)1098-2795(199904)52:4<427::AID-MRD12>3.0. $\mathrm{CO} ; 2-\mathrm{G})$

Briata P, Forcales SV, Ponassi M, Corte G, Chen CY, Karin M, Puri PL \& Gherzi R 2005 p38-dependent phosphorylation of the mRNA decaypromoting factor KSRP controls the stability of select myogenic transcripts. Molecular Cell 20 891-903. (doi:10.1016/j.molcel.2005. 10.021)

Brook M, Tchen CR, Santalucia T, Mcllrath J, Arthur JS, Saklatvala J \& Clark AR 2006 Posttranslational regulation of tristetraprolin subcellular localization and protein stability by p38 mitogen-activated protein kinase and extracellular signal-regulated kinase pathways. Molecular and Cellular Biology 26 2408-2418. (doi:10.1128/MCB.26.6.24082418.2006)

Calder MD, Madan P \& Watson AJ 2008 Bovine oocytes and early embryos express Staufen and ELAVL RNA-binding proteins. Zygote 16 161-168. (doi:10.1017/S096719940700456X)

Doherty AS, Mann MR, Tremblay KD, Bartolomei MS \& Schultz RM 2000 Differential effects of culture on imprinted $\mathrm{H} 19$ expression in the preimplantation mouse embryo. Biology of Reproduction 62 1526-1535. (doi:10.1095/biolreprod62.6.1526)

Evsikov AV, de Vries WN, Peaston AE, Radford EE, Fancher KS, Chen FH, Blake JA, Bult CJ, Latham KE, Solter D et al. 2004 Systems biology of the 2-cell mouse embryo. Cytogenetic and Genome Research 105 240-250. (doi:10.1159/000078195)

Fan XC \& Steitz JA 1998 Overexpression of HuR, a nuclear-cytoplasmic shuttling protein, increases the in vivo stability of ARE-containing mRNAs. EMBO Journal 17 3448-3460. (doi:10.1093/emboj/17.12.3448)

Fernandez-Gonzalez R, Moreira P, Bilbao A, Jimenez A, Perez-Crespo $M$, Ramirez MA, Rodriguez De Fonseca F, Pintado B \& Gutierrez-Adan A 2004 Long-term effect of in vitro culture of mouse embryos with serum on mRNA expression of imprinting genes, development, and behavior. PNAS 101 5880-5885. (doi:10.1073/pnas.0308560101)

Fong B, Watson PH \& Watson AJ 2007 Mouse preimplantation embryo responses to culture medium osmolarity include increased expression of CCM2 and p38 MAPK activation. BMC Developmental Biology 72. (doi:10.1186/1471-213X-7-2)

Gantt KR, Cherry J, Richardson M, Karschner V, Atasoy U \& Pekala PH 2006 The regulation of glucose transporter (GLUT1) expression by the RNA binding protein HuR. Journal of Cellular Biochemistry 99 565-574. (doi:10.1002/jcb.20950)

Gardner DK \& Leese HJ 1986 Non-invasive measurement of nutrient uptake by single cultured pre-implantation mouse embryos. Human Reproduction 1 25-27.

Goto Y, Noda Y, Mori T \& Nakano N 1993 Increased generation of reactive oxygen species in embryos cultured in vitro. Free Radical Biology and Medicine 15 69-75. (doi:10.1016/0891-5849(93)90126-F)

Guhaniyogi J \& Brewer G 2001 Regulation of mRNA stability in mammalian cells. Gene 265 11-23. (doi:10.1016/S0378-1119(01)00350-X)

Harlow GM \& Quinn P 1979 Foetal and placental growth in the mouse after pre-implantation development in vitro under oxygen conditions of 5 and 20\%. Australian Journal of Biological Sciences 32 363-369.

Ho Y, Doherty AS \& Schultz RM 1994 Mouse preimplantation embryo development in vitro: effect of sodium concentration in culture media on RNA synthesis and accumulation and gene expression. Molecular Reproduction and Development 38 131-141. (doi:10.1002/mrd. 1080380203)

Jain RG, Andrews LG, McGowan KM, Pekala PH \& Keene JD 1997 Ectopic expression of Hel-N1, an RNA-binding protein, increases glucose transporter (GLUT1) expression in 3T3-L1 adipocytes. Molecular and Cellular Biology 17 954-962.
Jones GM \& Trounson AO 1999 Blastocyst stage transfer: pitfalls and benefits. The benefits of extended culture. Human Reproduction 14 1405-1408. (doi:10.1093/humrep/14.6.1405)

Kidder GM, Green AF \& McLachlin JR 1985 On the use of alpha-amanitin as a transcriptional blocking agent in mouse embryos: a cautionary note. Journal of Experimental Zoology 233 155-159. (doi:10.1002/jez. 1402330123)

Kim YK, Furic L, Desgroseillers L \& Maquat LE 2005 Mammalian Staufen1 recruits Upf1 to specific mRNA $3^{\prime}$ UTRs so as to elicit mRNA decay. Cell 120 195-208. (doi:10.1016/j.cell.2004.11.050)

Kind KL, Collett RA, Harvey AJ \& Thompson JG 2004 Oxygen-regulated expression of GLUT1, GLUT-3 and VEGF in the mouse blastocyst. Molecular Reproduction and Development 70 37-44. (doi:10.1002/mrd. 20183)

Kovacic B \& Vlaisavljević V 2008 Influence of atmospheric versus reduced oxygen concentration on development of human blastocysts in vitro: a prospective study on sibling oocytes. Reproductive Biomedicine Online 17 229-236. (doi:10.1016/S1472-6483(10)60199-X)

Lai WS, Carballo E, Thorn JM, Kennington EA \& Blackshear PJ 2000 Interactions of $\mathrm{CCCH}$ zinc finger proteins with mRNA. Binding of tristetraprolin-related zinc finger proteins to $\mathrm{AU}$-rich elements and destabilization of mRNA. Journal of Biological Chemistry 275 17827-17837. (doi:10.1074/jbc.M001696200)

Madan P, Rose K \& Watson AJ 2007 Na/K-ATPase beta1 subunit expression is required for blastocyst formation and normal assembly of trophectoderm tight junction-associated proteins. Journal of Biological Chemistry 282 12127-12134. (doi:10.1074/jbc.M700696200)

Martin PM, Sutherland AE \& van Winkle LJ 2003 Amino acid transport regulates blastocyst implantation. Biology of Reproduction 69 1101-1108. (doi:10.1095/biolreprod.103.018010)

Meintjes M, Chantilis SJ, Douglas JD, Rodriguez AJ, Guerami AR, Bookout DM, Barnett BD \& Madden JD 2009 A controlled randomized trial evaluating the effect of lowered incubator oxygen tension on live births in a predominantly blastocyst transfer program. Human Reproduction 24 300-307. (doi:10.1093/humrep/den368)

Meister A 1994 Glutathione, ascorbate and cellular protection. Cancer Research 54S 1969-1975.

Moley KH, Chi M M-Y \& Mueckler MM 1998 Maternal hyperglycemia alters glucose transport and utilization in mouse preimplantation embryos. American Journal of Physiology 275 E38-E47.

Natale DR, Paliga AJ, Beier F, D'Souza SJ \& Watson AJ 2004 p38 MAPK signaling during murine preimplantation development. Developmental Biology 268 76-88. (doi:10.1016/j.ydbio.2003.12.011)

Niemann H \& Wrenzycki C 2000 Alterations of expression of developmentally important genes in preimplantation bovine embryos by in vitro culture conditions: implications for subsequent development. Theriogenology 53 21-34. (doi:10.1016/S0093-691X(99) $00237-X)$

Owen CM \& Segars JH Jr 2009 Imprinting disorders and assisted reproductive technologies. Seminars in Reproductive Medicine 27 417-428. (doi:10.1055/s-0029-1237430)

Pantaleon M, Ryan JP, Gil M \& Kaye PL 2001 An unusual subcellular localization of GLUT1 and link with metabolism in oocytes and preimplantation mouse embryos. Biology of Reproduction 64 1247-1254. (doi:10.1095/biolreprod64.4.1247)

Peng SS, Chen CY, Xu N \& Shyu AB 1998 RNA stabilization by the AU-rich element binding protein HuR, an ELAV protein. EMBO Journal 17 3461-3470. (doi:10.1093/emboj/17.12.3461)

Pfaffl MW 2001 A new mathematical model for relative quantification in real-time RT-PCR. Nucleic Acids Research 25 e45. (doi:10.1093/nar/29. 9.e45)

Phillips RS, Ramos SB \& Blackshear PJ 2002 Members of the tristetraprolin family of tandem $\mathrm{CCCH}$ zinc finger proteins exhibit CRM1-dependent nucleocytoplasmic shuttling. Journal of Biological Chemistry 277 11606-11613. (doi:10.1074/jbc.M111457200)

Rinaudo PF, Giritharan G, Talbi S, Dobson AT \& Schultz RM 2006 Effects of oxygen tension on gene expression in preimplantation mouse embryos. Fertility and Sterility 86 1252-1265. (doi:10.1016/j.fertnstert.2006.05. 017)

Rizos D, Gutierrez-Adan A, Perez-Garnelo S, De La Fuente J, Boland MP \& Lonergan P 2003 Bovine embryo culture in the presence or absence of 
serum: implications for blastocyst development, cryotolerance, and messenger RNA expression. Biology of Reproduction 68 236-243. (doi:10.1095/biolreprod.102.007799)

Saunders LR \& Barber GN 2003 The dsRNA binding protein family: critical roles, diverse cellular functions. FASEB Journal 17 961-983. (doi:10. 1096/fj.02-0958rev)

Sharova LV, Sharov AA, Nedorezov T, Piao Y, Shaik N \& Ko MSH 2009 Database of mRNA half-life of 19977 genes obtained by DNA microarray analysis of pluripotent and differentiating mouse embryonic stem cells. DNA Research 16 45-58. (doi:10.1093/dnares/dsn030)

Sinclair KD, McEvoy TG, Maxfield EK, Maltin CA, Young LE, Wilmut I, Broadbent PJ \& Robinson JJ 1999 Aberrant fetal growth and development after in vitro culture of sheep zygotes. Journal of Reproduction and Fertility 116 177-186. (doi:10.1530/jrf.0.1160177)

Song IS, Tatebe S, Dai W \& Kuo MT 2005 Delayed mechanism for induction of gamma-glutamylcysteine synthetase heavy subunit mRNA stability by oxidative stress involving p38 mitogen-activated protein kinase signaling. Journal of Biological Chemistry 280 28230-28240. (doi:10.1074/ jbc.M413103200)

St Johnston D, Beuchle D \& Nusslein-Volhard C 1991 Staufen, a gene required to localize maternal RNAs in the Drosophila egg. Cell 66 51-63. (doi:10.1016/0092-8674(91)90138-O)

Stover SK, Gushansky GA, Salmen JJ \& Gardiner CS 2000 Regulation of gamma-glutamate-cysteine ligase expression by oxidative stress in the mouse preimplantation embryo. Toxicology and Applied Pharmacology 168 153-159. (doi:10.1006/taap.2000.9030)

Tran H, Maurer F \& Nagamine Y 2003 Stabilization of urokinase and urokinase receptor mRNAs by HuR is linked to its cytoplasmic accumulation induced by activated mitogen-activated protein kinaseactivated protein kinase 2. Molecular and Cellular Biology 23 7177-7188. (doi:10.1128/MCB.23.20.7177-7188.2003)

Waldenström U, Engström A-B, Hellberg D \& Nilsson S 2009 Low-oxygen compared with high-oxygen atmosphere in blastocyst culture, a prospective randomized study. Fertility and Sterility 91 2461-2465. (doi:10.1016/j.fertnstert.2008.03.051)
Watkins AJ, Platt D, Papenbrock T, Wilkins A, Eckert JJ, Kwong WY, Osmond C, Hanson M \& Fleming TP 2007 Mouse embryo culture induces changes in postnatal phenotype including raised systolic blood pressure. PNAS 104 5449-5454. (doi:10.1073/pnas.0610317104)

Watson AJ, De Sousa P, Caveney A, Barcroft LC, Natale D, Urquhart J \& Westhusin ME 2000 Impact of bovine oocyte maturation media on oocyte transcript levels, blastocyst development, cell number, and apoptosis. Biology of Reproduction 62 355-364. (doi:10.1095/biolreprod62.2.355)

Whitten WK \& Biggers JD 1968 Complete development in vitro of the pre-implantation stages of the mouse in a simple chemically defined medium. Journal of Reproduction and Fertility 17 399-401. (doi:10. 1530/jrf.0.0170399)

van Winkle LJ 2001 Amino acid transport regulation and early embryo development. Biology of Reproduction 64 1-12. (doi:10.1095/biolreprod64.1.1)

Xie Y, Wang F, Puscheck EE \& Rappolee DA 2007 Pipetting causes shear stress and elevation of phosphorylated stress-activated protein kinase/jun kinase in preimplantation embryos. Molecular Reproduction and Development 74 1287-1294. (doi:10.1002/mrd.20563)

Yaman I, Fernandez J, Sarkar B, Schneider RJ, Snider MD, Nagy LE \& Hatzoglou M 2002 Nutritional control of mRNA stability is mediated by a conserved $\mathrm{AU}$-rich element that binds the cytoplasmic shuttling protein HuR. Journal of Biological Chemistry 277 41539-41546. (doi:10.1074/ jbc.M204850200)

Zeng F, Baldwin DA \& Schultz RM 2004 Transcript profiling during mouse preimplantation development. Developmental Biology 272 483-496. (doi:10.1016/j.ydbio.2004.05.018)

Received 18 March 2011

First decision 9 May 2011

Revised manuscript received 14 July 2011

Accepted 16 August 2011 